\title{
The influence to mine hoisting steel wire rope tension and deformation from load and elastic modulus
}

\author{
Jisheng Wang ${ }^{1}$, Chengming Wang ${ }^{1,2,3, a}$, Bo Du ${ }^{1}$ \\ ${ }^{1}$ Citic heavy industry machinery co., LTD, Luoyang, Henan 471000, China. \\ ${ }^{2}$ School of Mechanical and Electrical Engineering, China University of Mining\&Technology, \\ Xuzhou, Jiangsu 221008,China. \\ ${ }^{3}$ School of Mechanical Engineering , Zhengzhou University, Zhengzhou, henan 450001, \\ China. \\ ahitwcm@zzu.edu.cn
}

Keywords: steel wire rope; Simulink ; load; elastic modulus; vibration frequency

Abstract: For studying the influence to mine hoisting steel wire rope tension and deformation from load and elastic modulus, according to the differential equation of mine hoisting steel wire rope tension and deformation, we establish the corresponding dynamic simulation model using Matlab-Simulink, carry out simulation experiments respectively through 3 working conditions according to the simulated test parameters, get variation rule of rope tension and deformation in the lifting and descending process, study the influence to tension and deformation and vibration frequency from the load and elastic modulus, provide the theoretical basis and data support for hoisting system design.

Fund Project: National 973 project funding (ID: 2014CB049401, 2014CB049402)

\section{Introduction}

Deep resource exploration is the national development strategy, the ultra-deep mine large hoist equipment is the key equipment to develop deep resources exploration, the hoisting system test platform is the earlier period research foundation of ultra-deep mine large lift equipment, hoisting rope plays a very important role in the hoisting system. In this paper, we carried out model creation and simulation analysis on the steel wire rope of the simulation test station, studied the variation rule of the tension and deformation in the processes of lifting and descending, provided the load data which is necessary in the process of design and manufacture of ultra deep mine lifting equipment.

\section{Mathematical Model of Mine Hoisting Steel Wire Rope}

The hoisting speed which is shown in figure 1, is a three-stage process, absolute value of the acceleration and deceleration phase is equal, and wire rope simplified mechanical model is shown in figure 2 .

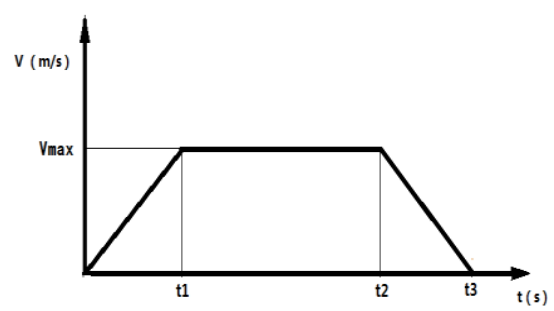

Fig1. The velocity diagram of steel wire rope of steel wire rope

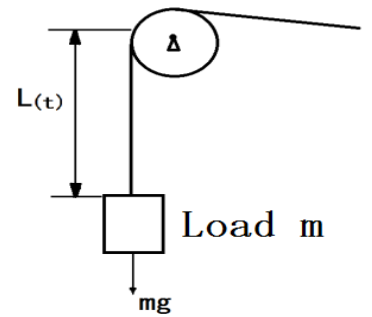

Fig2 .The simplified mechanical model

Damping of hoisting system and the steel wire rope, relative slip between steel wire rope and hoisting sheave, and rigidity of other parts are ignored. Under the above assumptions, in the lifting 
and descending processes, we establish differential equations of steel wire rope tension and deformation respectively ${ }^{[1-3]}$.

Differential equation of steel wire rope tension in lifting process:

$$
\frac{d^{2} F}{d t^{2}}=\left\{E S\left(g-\frac{d^{2} L}{d t^{2}}\right)-\left[E S /(m+\rho L / 3)-\frac{d^{2} L}{d t^{2}}\right] F+2 \frac{d L}{d t} \frac{d F}{d t}\right\} / L
$$

Differential equation of steel wire rope deformation in lifting process:

$$
\frac{d^{2} U}{d t^{2}}=g-\frac{d^{2} L}{d t^{2}}-\left[E S\left(U_{0}+U\right)\right] /[(m+\rho L / 3) L]
$$

Differential equation of steel wire rope tension in descending process:

$$
\frac{d^{2} F}{d t^{2}}=\left\{E S\left(g-\frac{d^{2} L}{d t^{2}}\right)-\left[E S /(m+\rho L / 3)+\frac{d^{2} L}{d t^{2}}\right] F-2 \frac{d L}{d t} \frac{d F}{d t}\right\} / L
$$

Differential equation of steel wire rope deformation in descending process:

$$
\frac{d^{2} U}{d t^{2}}=g-\frac{d^{2} L}{d t^{2}}-\left[E S\left(U_{0}+U\right)\right] /[(m+\rho L / 3) L]
$$

In the formula

$F$ - Tension of steel wire rope on the hoisting sheave, N.

$E \_$Elastic modulus of steel wire rope, MPa.

$S \_$cross-sectional area of steel wire rope, $\mathrm{mm}^{2}$.

$g \quad$ gravity acceleration, $\mathrm{m} / \mathrm{s}^{2}$.

$m$ _ hoist load of steel wire rope, $\mathrm{kg}$.

$\rho$ __linear density of steel wire rope, $\mathrm{kg} / \mathrm{m}$.

$L \_$the suspension length of the steel wire rope from hoisting sheave side, $\mathrm{m}$.

$t$ _lift time, s.

$U_{0} \_$initial elongation of steel wire rope, $\mathrm{m}$.

$U \ldots$ the rope-end deformation in the place Connected to the cage, $\mathrm{m}$.

\section{The Creation of Steel Wire Rope Dynamic Simulation Model}

Aimed at mine hoisting steel wire rope, senior scholars have carried out a lot of research $^{[4-7]}$. According to differential equations, we establish the tension and deformation model which are shown in Figure 3 and Figure 4, by MATLAB-Simulink simulation software. And in the model, the steel wire rope tension $F$ at the hoisting sheave, tension change rate $F^{\prime}$, tension change acceleration $F^{\prime \prime}$ and the rope-end deformation $U$, deformation rate $U^{\prime}$, deformation acceleration $U^{\prime \prime}$ are shown respectively. The tension model and the deformation model in lifting and descending process are similar,so here does not make the details. 


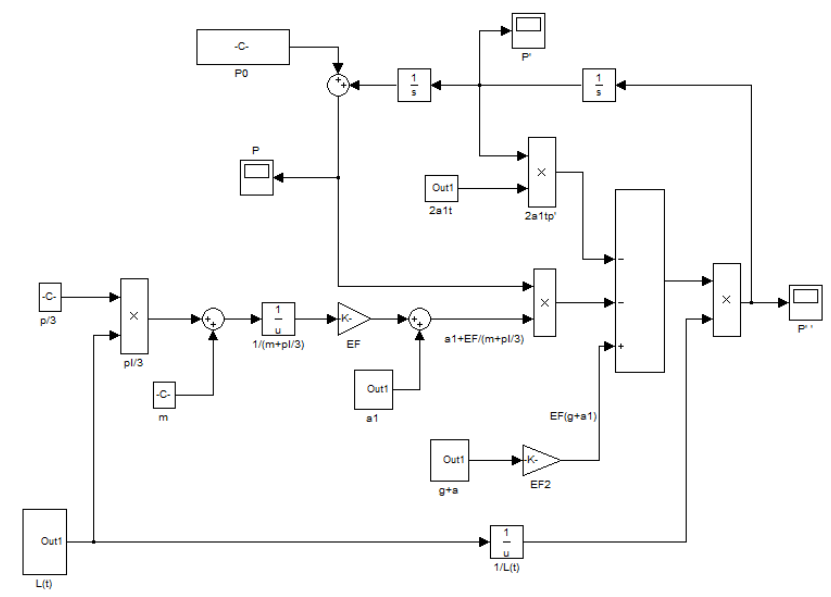

Fig.3 The tension simulation model of the steel wire rope in lifting process

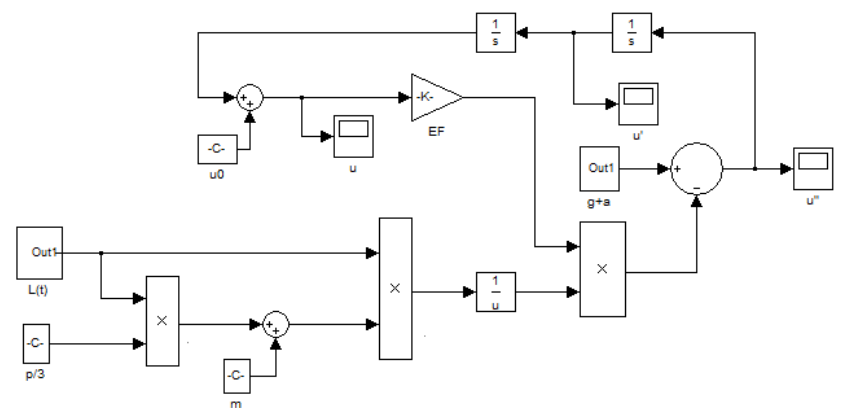

Fig.4 The deformation simulation model of the end of steel wire rope in lifting process

\section{Simulation Parameters and Results Analysis of the Steel Wire Rope}

\section{Simulation Parameters}

Combined with ultra deep mine large lifting equipment test platform of CITIC Heavy Industry, the base condition (condition 1) simulation parameters are:

Steel wire rope hoisting load is $1000 \mathrm{~kg}$, steel wire rope line density is $0.41 \mathrm{~kg} / \mathrm{m}$, steel wire rope elastic modulus is $10^{5} \mathrm{MPa}$, cross-sectional area is $52.36 \mathrm{~mm}^{2}$, accelerated speed of both acceleration and deceleration in the lifting process are $0.75 \mathrm{~m} / \mathrm{s}^{2}$, acceleration of gravity is $9.8 \mathrm{~m} / \mathrm{s}^{2}$, the maximum speed is $1.8 \mathrm{~m} / \mathrm{s}$, the initial rope length is $5 \mathrm{~m}$, effective hoisting height is $30 \mathrm{~m}$.

Simulation Results and Analysis of Lifting Process of the Base Condition (Condition 1)

The tension and deformation variation rule of base condition (condition 1) are shown in Figure 5 and Figure 6.

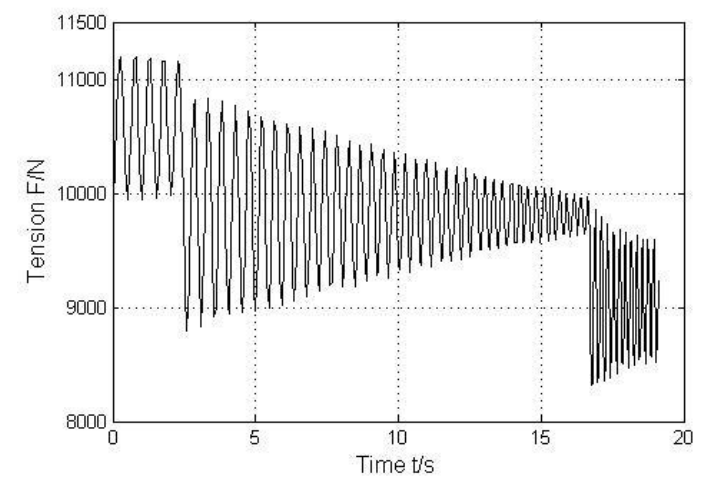

Fig5. The tension curve in lifting process of working condition 1 


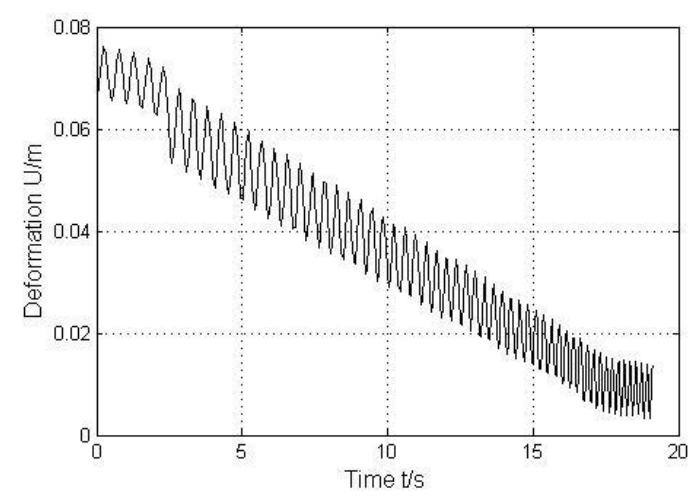

Fig6 .The deformation curve in lifting process of working condition 1

Through simulation experiments, the maximum tension is $\mathrm{F}_{\max 1}=1.1196 \times 10^{4} \mathrm{~N}$, occurring in the first vibration period of acceleration phase. The minimum tension $F_{\min 1}=8318 \mathrm{~N}$, occurring in the first vibration period of deceleration phase. The maximum and minimum tension can't be got by the calculation and analysis of the dynamic formula.

For condition 1, the maximum deformation is $U_{\max 1}=0.076 \mathrm{~m}$, occurring in the first vibration period of acceleration phase. The minimum deformation is $\mathrm{U}_{\min 1}=0.004 \mathrm{~m}$, occurring in the last vibration period of deceleration phase.

When the lifting conveyance is at the lowest position, the calculated value of the system's natural frequency is $1.947627475 \mathrm{~Hz}$, and the simulation value is $1.953697372 \mathrm{~Hz}$; when the lifting conveyance is at the highest position, the calculated value of the system's natural frequency is $5.152941042 \mathrm{~Hz}$, and the simulation value is $4.79616307 \mathrm{~Hz}$.

\section{Simulation Results and Analysis of Descending Process of the Base Condition (Condition 1)}

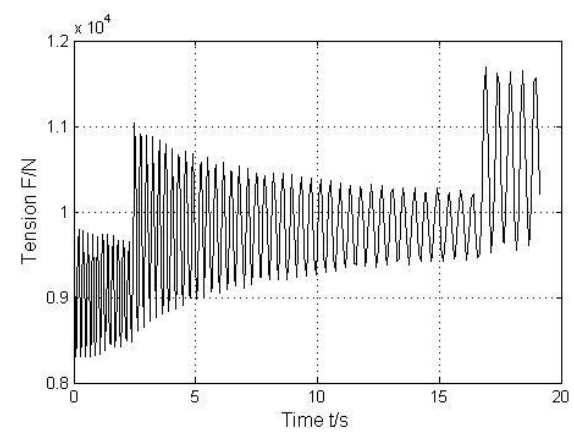

Fig.7 The tension curve in descending process of working condition 1

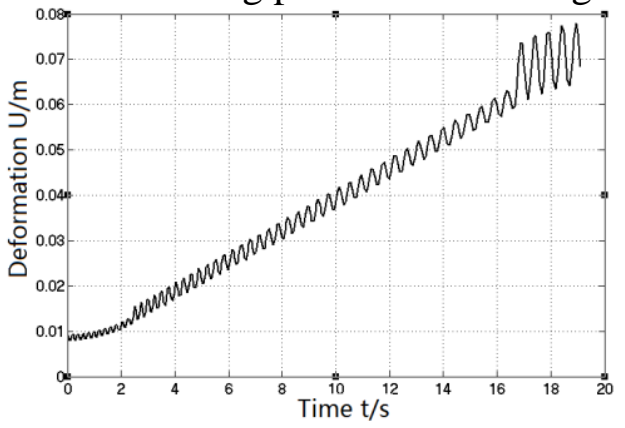

Fig. 8 The deformation curve in descending process of working condition 1

For the descending process, the maximum tension is $\mathrm{F}_{\mathrm{f}-\max 1}=1.1688 \times 10^{4} \mathrm{~N}$, occurring in the first vibration period of deceleration phase. The minimum tension $\mathrm{F}_{\mathrm{f}-\mathrm{min} 1}=8304 \mathrm{~N}$, occurring in the second vibration period of acceleration phase.

For the descending process, the maximum deformation is $\mathrm{U}_{\mathrm{f}-\max 1}=0.0779 \mathrm{~m}$, occurring in the last vibration period of deceleration phase. The minimum deformation $\mathrm{U}_{\mathrm{f}-\mathrm{min} 1}=0.00797 \mathrm{~m}$, occurring in the first vibration period of acceleration phase. 
When the lifting conveyance is at the lowest position, the simulation value of the system natural frequency is $1.779676099 \mathrm{~Hz}$; and when the lifting conveyance is at the highest position, the simulation value of the system natural frequency is $4.938271605 \mathrm{~Hz}$. During the descending process, the system vibration frequency decreases with the increase of the rope length.

\section{The Simulation Results and Analysis of Lifting Process of Working Condition 2}

The parameter setting of condition 2 is changing the hoisting load to $750 \mathrm{~kg}$, and other parameters are same with standard condition. The variation rule of tension and deformation are shown in Figure 9 and Figure10.

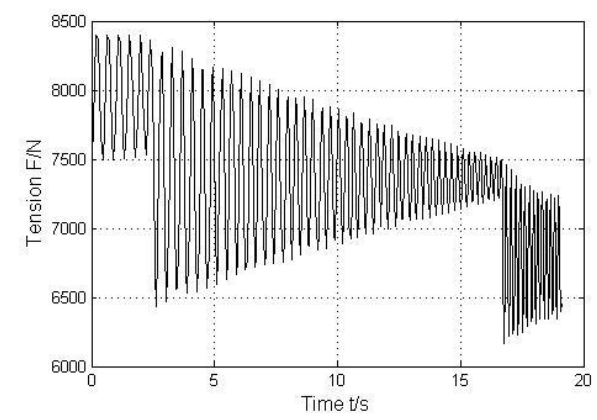

Fig.9 The tension curve in lifting process of working condition 2

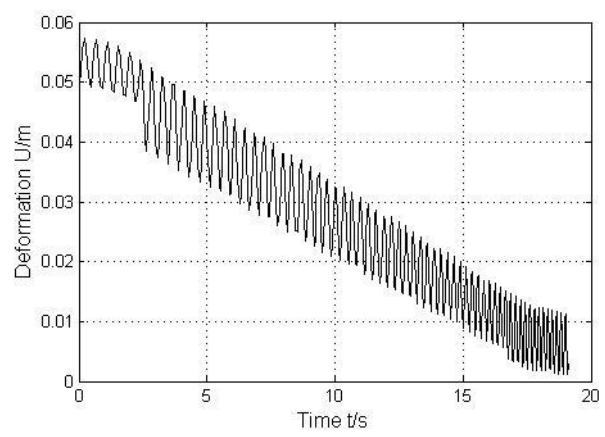

Fig.10 The deformation curve in lifting process of working condition 2

The maximum tension of condition 2 is $F_{\max 2}=8396 \mathrm{~N}$, occurring in the third vibration period of acceleration phase, and minimum tension is $F_{\min 2}=6170 \mathrm{~N}$, occurring in the first vibration period of decelerating phase.

The maximum deformation of condition 2 is $U_{\max 2}=0.0573 \mathrm{~m}$, occurring in the first vibration period of acceleration phase; and minimum deformation is $\mathrm{U}_{\min 2}=0.0011778 \mathrm{~m}$, occurring in the last but one vibration cycles period of the decelerating phase.

When the lifting conveyance is at the lowest position, the calculated value of nature frequency of the system is $2.248927846 \mathrm{~Hz}$, and the simulation value is $2.212878956 \mathrm{~Hz}$; when the lifting conveyance is at the highest position, the calculated value of nature frequency of the system is $5.950103798 \mathrm{~Hz}$, and the simulation value is $5.497526113 \mathrm{~Hz}$. 


\section{The Simulation Results and Analysis of Descending Process of Working Condition 2}

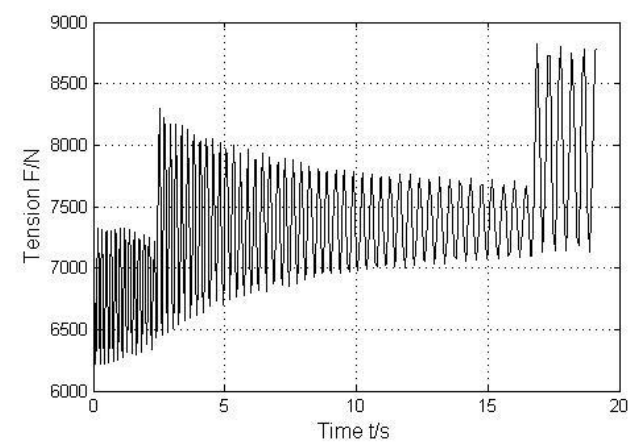

Fig.11 The tension curve in descending process of working condition 2

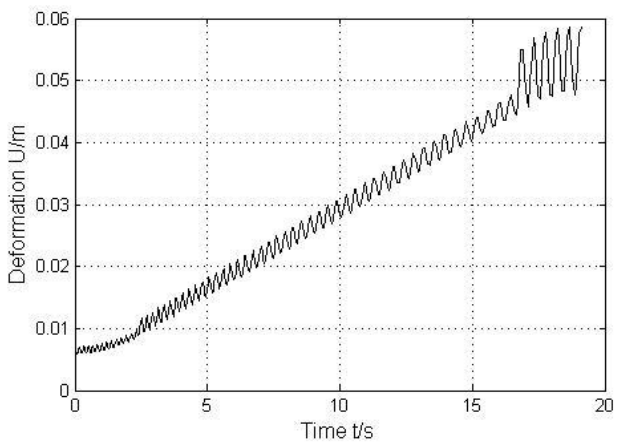

Fig.12 The deformation curve in descending process of working condition 2

Maximum tension is $\mathrm{F}_{\mathrm{f}-\max 2}=8823 \mathrm{~N}$, occurring in the first vibration period of decelerating phase; and minimum tension is $\mathrm{F}_{\mathrm{f}-\mathrm{min} 2}=6218 \mathrm{~N}$, occurring in the first vibration period of acceleration phase.

Maximum deformation of working condition 2 is $\mathrm{U}_{\mathrm{f}-\max 2}=0.0587 \mathrm{~m}$, occurring in the last vibration period of decelerating phase; and minimum deformation is $U_{\mathrm{f}-\min 2}=0.00599 \mathrm{~m}$, occurring in the first vibration period of acceleration phase.

When the hoisting conveyance is at the lowest position, the simulation value of nature frequency of the system is $2.242655304 \mathrm{~Hz}$, and when it is at the highest position, the simulation value is $5.592841163 \mathrm{~Hz}$.

Comparing working condition 2 with working condition 1 , no matter when the hoisting conveyance is at the lowest or highest position, no matter calculated value or simulation value, and no matter lifting process or descending process, the nature frequency of the system of condition 2 is bigger than condition 1.

This illustrates that the decrease of the lifting load leads to the increase of the vibration frequency, and that is because the vibration frequency and square root of mass concern into inverse ratio.

In the lifting process, the ratio of maximum tension between condition 2 and condition 1 is $\mathrm{F}_{\max 2} /$ $\mathrm{F}_{\max 1}=74.988 \%$, and the ratio of minimum tension is $\mathrm{F}_{\min 2} / \mathrm{F}_{\min 1}=74.176 \%$.

In the descending process, the ratio of maximum tension between condition 2 and condition 1 is $\mathrm{F}_{\mathrm{f}-\max 2} / \mathrm{F}_{\mathrm{f}-\max 1}=75.4877 \%$, and the ratio of minimum tension is $\mathrm{F}_{\mathrm{f}-\mathrm{min} 2} / \mathrm{F}_{\mathrm{f}-\min 1}=74.8796 \%$. This illustrates that no matter lifting process or descending process, the maximum tension and minimum tension are in proportion to the load.

In the lifting process, the ratio of maximum deformation between condition 2 and condition 1 is $\mathrm{U}_{\max 2} / \mathrm{U}_{\max 1}=75.3947 \%$.

In the descending process, the ratio of maximum deformation between condition 2 and condition 1 is $\mathrm{U}_{\mathrm{f}-\max 2} / \mathrm{U}_{\mathrm{f}-\max 1}=75.353 \%$, This illustrates that both in lifting process and in descending process, the maximum deformation is in proportion to the load.

\section{The Simulation Results and Analysis of Lifting Process of Working Condition 3}

The parameter setting of condition 3 is changing the elastic modulus of steel wire rope to 
$1.25 \times 10^{5} \mathrm{MPa}$, and other parameters are same with standard working condition. The variation rule of tension and deformation are shown in Figure 13 and Figure 14.

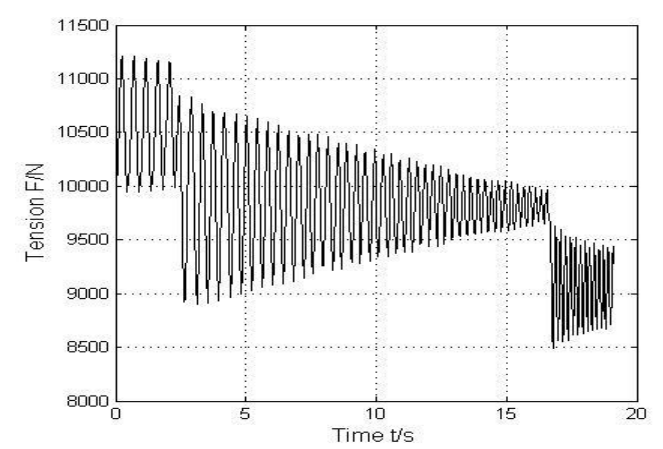

Fig.13 The tension curve in lifting process of working condition 3

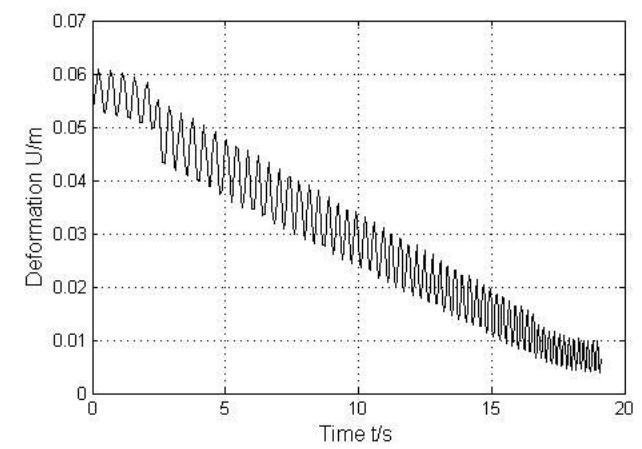

Fig.14 The deformation curve in lifting process of working condition 3

The maximum tension of condition 3 is $\mathrm{F}_{\max 3}=1.1212 \times 10^{4} \mathrm{~N}$, occurring in the first vibration period of acceleration phase, a little bigger than $\mathrm{F}_{\max 1}=1.1196 \times 10^{4} \mathrm{~N}$. The minimum tension of condition 3 is $\mathrm{F}_{\min 3}=8488 \mathrm{~N}$, occurring in the first vibration period of decelerating phase, a little bigger than $\mathrm{P}_{\min 1}=8318 \mathrm{~N}$.

The maximum deformation of condition 3 is $U_{\max 3}=0.0609 \mathrm{~m}$, occurring in the first vibration period of acceleration phase, the minimum deformation is $\mathrm{U}_{\min 3}=0.003935 \mathrm{~m}$, occurring in the last vibration period of decelerating phase.

When the hoisting conveyance is at the lowest position, the calculated value of nature frequency of the system is $2.177515023 \mathrm{~Hz}$, and the simulation value is $2.202158115 \mathrm{~Hz}$; when the hoisting conve yance is at the highest position, the calculated value of nature frequency of the system is $5.761163246 \mathrm{~Hz}$, and the simulation value is $6.211180124 \mathrm{~Hz}$.

\section{The Simulation Results and Analysis of Descending Process of Working Condition 3}

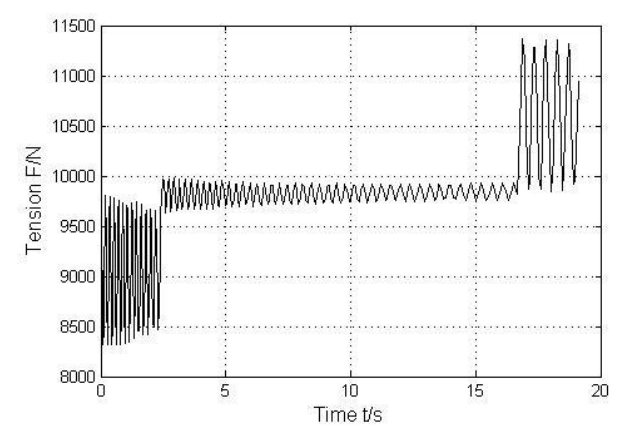

Fig.15 The tension curve in descending process of working condition 3 


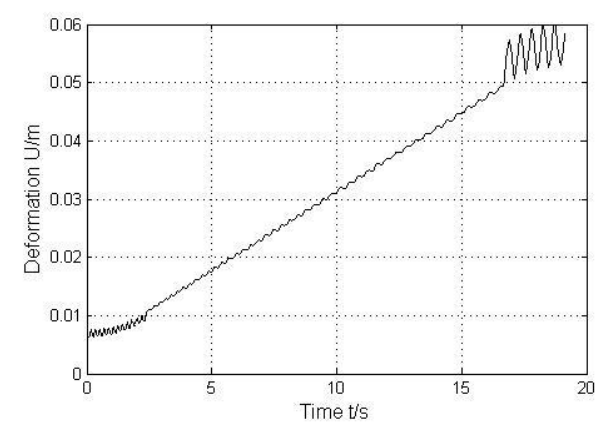

Fig.16 The deformation curve in descending process of working condition 3

Maximum tension is $\mathrm{F}_{\mathrm{f}-\max 3}=1.1368 \times 10^{4} \mathrm{~N}$, occurring in the first vibration period of decelerating phase; and minimum tension is $\mathrm{F}_{\mathrm{f}-\mathrm{min} 3}=8315 \mathrm{~N}$, occurring in the fourth vibration period of acceleration phase.

Maximum deformation of working condition 3 is $\mathrm{U}_{\mathrm{f}-\max 3}=0.0599 \mathrm{~m}$, occurring in the last vibration period of decelerating phase; and minimum deformation is $\mathrm{U}_{\mathrm{f}-\min 3}=0.00639 \mathrm{~m}$, occurring in the first vibration period of acceleration phase.

When the hoisting conveyance is at the lowest position, the simulation value of nature frequency of the system is $2.256826901 \mathrm{~Hz}$, and when it is at the highest position, the value is $5.595970901 \mathrm{~Hz}$.

Summarizing the simulation experiment data of lifting process and descending process of condition 3, no matter the hoisting conveyance is at the lowest or highest position, no matter the calculated value or simulation value, and no matter lifting process or descending process, the nature frequency of condition 3 is bigger than condition 1, this illustrates that increase of the modulus of elasticity makes the increase of the vibration frequency, and that is because the vibration frequency is in proportion to square root of elastic modulus.

From the tension simulation data, the increase of elastic modulus has almost no influence to tension.

The maximum deformation and minimum deformation of working condition 3 are smaller than condition 1 respectively, because compared to condition 1, the maximum tension and minimum tension of condition 3 remain basically unchanged, but the increase of elastic modulus lead to the increase of the wire rope rigidity. Umax $1 / \mathrm{Umax} 3=1.2479$, therefore, maximum deformation and elastic modulus concern into inverse ratio.

\section{Laws and Analysis}

Respectively aiming at the 3 working conditions, dividing every condition into lifting process and descending process, and analyzing the two processes of all conditions one by one, the analysis shows that:

The tension and deformation law of condition 2 and condition 3 are roughly similar to condition 1 , that is to say, tension and deformation in the entire lifting process and descending process have apparent three phase change law, and the change relatively smooth in every phase.

The maximum tension, minimum tension, and maximum deformation have a little difference of the lifting process and descending process in the same condition, but the minimum deformation have a greater difference.

No matter descending process or descending process, compared to condition 1, the load-dropping of condition 2 lead to the nature frequency of system increase, and maximum tension, minimum tension, maximum deformation and minimum deformation decrease, and maximum tension, minimum tension , maximum deformation are proportional to load mainly.

No matter lifting process or descending process, compared to condition 1, elastic modulus increase of condition 3, lead to the nature frequency of system increase, maximum tension and minimum tension are almost invariant, and maximum deformation and minimum deformation decrease, and maximum deformation and elastic modulus concern into inverse ratio. 


\section{Summary}

Based on simulation test bed, setting 3 conditions and making simulation experiments respectively, the experiment results showed that: load has a evident influence to tension, deformation, and vibration frequency, but elastic modulus has almost no influence to tension and some influence to deformation and vibration frequency.

The mutation of tension and deformation in the simulation curves will affect steel wire rope service life, which needs sufficient attention. It's impossible to get the simulation data by statics and dynamics computation alanalysis simply, and the simulation data is more real and reasonable. The simulation data and curves are contributed to understanding wire rope vibration deformation regularity and force situation of the hosting wire, which can provides data support for the design of the hoisting system. Simulation test can predict the value of maximum tension and maximum deformation, position, and moment, so that preventive action can be done timely in engineering application.

Author: Jisheng Wang, Male, born in 1956,Professor of Engineering,subject matter expert of national 863 project of advanced manufacturing field,enjoying State Council special allowance, Henan zhongyuan scholar,chief engineer of Citicheavy industry machinery co., LTD, chief of State Key Laboratory of heavy mining equipment, now mainly working on mine heavy equipment research and development, and technological innovation management of the company.

Corresponding author:Chengming Wang, Male, born in 1980, postdoctor, lecturer, postgraduate tutor, mainly working on the research of mine hoisting system dynamics.

\section{References}

[1] H.X.Chen, S.Liu, Q.T.Tang. Dynamic simulation and analysis of mine hoisting cable based on SIMULINK[J]. Mining \& Processing Equipment,2008(9):44-47.

[2] S.R.Yan, B.C.Wen. The computer simulation of hoisting rope tension[J].Coal Mine Machinery, 1998(3):4-6.

[3] Y.X.PENG, Z.C.ZHU, G.A.Chen. Theoretical analysis of thermoviscoelastic contact between friction lining and wire rope in mine friction hoists. Mining Science and Technology,2009(19):0518-0521.

[4] Kaczmarczyka S, Ostachowicz W. Transient vibration phenomena in deep mine hoisting cables. Part 2: Numerical simulation of the dynamic response.J Sound Vib 2003(262):245-289.

[5] Etsujiro I, Takao N, Takahiro K. Dynamic simulation of wire rope with contact. J Mech Sci Technol 2009(23):1083-1088.

[6]J.H.Bao, P.Zhang, C.M.Zhu, W.Sun.Transverse vibration of flexible hoisting rope with time-varying length. Journal of Mechanical Science and Technology 2014.28 (2) :457-466.

[7]P.Peterka, J.Krešak, S.Kropuch, G.Fedorko, V.Molnar, M.Vojtko.Failure analysis of hoisting steel wire rope. Engineering Failure Analysis 2014 (45): 96-105. 